\title{
Mechanisms of levetiracetam in the control of status epilepticus and epilepsy
}

\author{
Laxmikant S. Deshpande' and Robert J. DeLorenzo ${ }^{1,2,3}$ * \\ 1 Department of Neurology, Virginia Commonwealth University, Richmond, VA, USA \\ ${ }^{2}$ Department of Pharmacology and Toxicology, Virginia Commonwealth University, Richmond, VA, USA \\ ${ }^{3}$ Department of Biochemistry, Virginia Commonwealth University, Richmond, VA, USA
}

Edited by:

Batool F. Kirmani, Texas A\&M Health

Science Center, USA

\section{Reviewed by:}

Lee A. Shapiro, Texas A\&M Health

Science Center College of Medicine USA

Ekokobe Fonkem, Beth Israel

Deaconess Medical Center, USA

*Correspondence:

Robert J. DeLorenzo, School of

Medicine, Virginia Commonwealth

University, PO Box 980599

Richmond, VA 23298, USA

e-mail: rdeloren@hsc.vcu.edu
Status epilepticus (SE) is a major clinical emergency that is associated with high mortality and morbidity. SE causes significant neuronal injury and survivors are at a greater risk of developing acquired epilepsy and other neurological morbidities, including depression and cognitive deficits. Benzodiazepines and some anticonvulsant agents are drugs of choice for initial SE management. Despite their effectiveness, over $40 \%$ of SE cases are refractory to the initial treatment with two or more medications. Thus, there is an unmet need of developing newer anti-SE drugs. Levetiracetam (LEV) is a widely prescribed anti-epileptic drug that has been reported to be used in SE cases, especially in benzodiazepine-resistant SE or where phenytoin cannot be used due to allergic side-effects. Levetiracetam's nonclassical anti-epileptic mechanisms of action, favorable pharmacokinetic profile, general lack of central depressant effects, and lower incidence of drug interactions contribute to its use in SE management. This review will focus on LEV's unique mechanism of action that makes it a viable candidate for SE treatment.

Keywords: levetiracetam, calcium homeostasis, status epilepticus, anti-epileptic, mechanisms

\section{STATUS EPILEPTICUS: DEFINITION, CAUSES AND CONSEQUENCES}

Status epilepticus (SE) is a neurological emergency associated with a significant morbidity and mortality (1). It is defined as continuous seizure activity lasting greater than $30 \mathrm{~min}$ or intermittent seizures without regaining consciousness lasting for $30 \mathrm{~min}$ or longer (2). An operational definition of SE has also been proposed that suggests any seizures lasting more than 5 min to be considered SE and immediate steps taken to stop it to limit further morbidity and mortality (3). SE affects approximately 200,000 people annually and accounts for as many as 55,000 deaths per year in the United States alone (1). The economic burden of SE is also high with SE patients having 30-60\% higher reimbursements than patients admitted for other acute health problems, including acute myocardial infarction or congestive heart failure (4). SE can be caused by acute symptomatic processes such as metabolic disturbances (for example, electrolyte imbalance, renal failure, and sepsis), CNS infection, stroke, head trauma, drug toxicity, and hypoxia (5-7). Chronic symptomatic processes that cause SE include pre-existing epilepsy or the discontinuation of anti-epileptic drugs, chronic ethanol abuse and withdrawal, and remote processes such as CNS tumors or stroke (5-7). SE can be convulsive or non-convulsive, and under both situations SE can cause significant brain damage particularly in the limbic system $(8,9)$. SE patients are at a higher risk of developing acquired epilepsy $(10,11)$. About $12-30 \%$ of adults with a new diagnosis of epilepsy first present in SE $(10,11)$. Further, survivors of SE suffer from other neurological problems including depression, cognitive deficits, and suicidal ideations (12).

\section{TREATMENT OF SE}

It is extremely important to recognize and control SE since prolonged SE can quickly develop into refractory SE, which is very difficult to treat (13). In addition, prompt SE treatment is essential to prevent mortality and the progressive brain damage that produces neurological morbidities. Treatment of SE (14) begins with medical stabilization of the patient with an initial focus on respiratory and circulatory stabilization. Further evaluations are then made looking for underlying causes of SE (metabolic disturbances, infections, etc.) and treatments are provided to correct them. Following these emergency stabilizations of the patient's physiological status, treatment of SE is rapidly initiated using currently accepted first line drugs for stopping SE. This usually includes immediate treatment with benzodiazepines such as midazolam, diazepam, or lorazepam. The second-line of drugs to control SE include fosphenytoin, phenytoin, phenobarbital, and valproic acid. Despite the effectiveness of benzodiazepines and other anticonvulsant drugs in treating seizures, prolonged SE becomes refractory to treatment with currently available anticonvulsant agents treatment in over $40 \%$ of SE cases becoming refractory to the initial treatment with two or more medications (13). Clinical trials have shown that patients treated within $20 \mathrm{~min}$ of SE had better prognoses than those who did not respond within $20 \mathrm{~min}$ (15). However, epidemiological studies have shown that time to seizure treatment varies broadly with only about $41 \%$ of all patients receiving their first anti-epileptic drug within $30 \mathrm{~min}$ (16). In addition, termination of SE with benzodiazepines or phenytoin was effective in $80 \%$ of patients when administered within $30 \mathrm{~min}$ of seizure onset, but this effectiveness decreased to less than $40 \%$ when treatment 
was initiated several hours after seizure onset (17). In such a scenario, the treatment options become extremely limited to drugs such as pentobarbital, midazolam, or propofol. Topiramate and ketamine are used as additive agents to benzodiazepines and first line drugs to control refractory SE (18). However drug interactions, side-effects, pharmacoresistance, CNS depression, all add to the medical complexity of treating SE effectively and highlight the need to develop additional agents to treat SE. Thus, there is an unmet need of developing newer anti-SE drugs.

\section{LEV FOR THE TREATMENT OF SE}

Levetiracetam (LEV) $[(S)$ - $\alpha$-ethyl-2-oxo-1-pyrrolidine acetamide $]$ is a broad-spectrum anti-epileptic drug that was approved by the US Food and Drug Administration in 1999 and has quickly become one of the widely prescribed drugs for the treatment of partial and generalized epilepsy. While it is structurally unrelated to other anti-epileptic drugs, it is structurally related to nootropic agent piracetam. Levetiracetam is not considered a substrate for multidrug transporters (19). The multi-drug transporter proteins are thought to be responsible for altering drug concentrations at the site of action by affecting drug uptake or increasing transport of drug cleaving enzymes. Increased expression of multi-drug transporter proteins is hypothesized to be a major mechanism for developing pharmacoresistance (20). This could explain the low probability of pharmacoresistance for LEV, despite daily chronic intake of the medication. In addition, minimal drug interactions, fewer side-effects, and broad-spectrum efficacy have all contributed to LEV's ever widening use for the treatment of seizures. These characteristics make LEV a strong candidate for second-line treatment of SE, especially in patients with refractory SE and where use of phenytoin is deemed inappropriate due to allergic side-effects (21). With the recent introduction of an intravenous preparation of $\mathrm{LEV}$, there has been considerable interest in the use of LEV for the treatment of SE (22), although LEV is not approved for this indication. There are recent studies and review articles that discuss the use of LEV in the management of SE (18, 21, 23-28). The rest of this article will mainly focus on the molecular targets and unique mechanism of actions of LEV that makes it such an attractive drug candidate for not only the treatment of SE, but also other neurological disorders such as Huntington's chorea (29), Tardive dyskinesia (30), Tourette syndrome (31), anxiety disorders (32), traumatic brain injury and stroke (33), amongst others.

\section{UNIQUE ANTICONVULSANT PROPERTY OF LEV}

Currently, little is known regarding the mechanism underlying LEV's anti-epileptic action. The discovery of LEV's anticonvulsant activity is unique. It was devoid of anticonvulsant activity in the acute maximal electroshock seizure test and in the maximal chemoconvulsive seizure test in pre-clinical assays (34). However, a potent protection was observed against partial epileptic seizure activity induced by pilocarpine and kainic acid (34). It also exhibited anticonvulsant activity against kindled seizures and in the Strasbourg genetic absence epilepsy rats (35). Studies attempting to elucidate LEV's anticonvulsant action revealed a unique profile of mechanisms (36). Surprisingly, it did not exhibit the classical action in that LEV had no effect on voltage-dependent $\mathrm{Na}^{+}$channels, GABAergic transmission, or affinity for either GABAergic or glutamatergic receptors (37). These represent the most common mechanisms of action for the vast majority of anti-epileptic drugs. In light of these studies, multiple laboratories focused on elucidating the molecular mechanisms that make LEV a potent anti-epileptic and SE drug. The following sections highlight the unique properties of LEV as an anticonvulsant agent.

\section{EFFECTS OF LEV ON NEUROTRANSMITTER RELEASE}

Research has revealed several unique mechanisms for the anticonvulsant effects of LEV. Levetiracetam has been shown to affect GABA turnover in the striatum and decrease levels of the amino acid taurine, a low affinity agonist for $\mathrm{GABA}_{\mathrm{A}}$ receptors, in the hippocampus with no effect in other amino acids (38). In addition, $\mathrm{LEV}$ removed the $\mathrm{Zn}^{2+}$-induced suppression of $\mathrm{GABA}_{\mathrm{A}}$-mediated presynaptic inhibition, resulting in a presynaptic decrease in glutamate mediated excitatory transmission (39). Other reports have also suggested that the mechanisms of the anti-epileptic and neuroprotective actions of LEV seem to be mediated, at least in part, through the combination of inhibitory effects on depolarizationinduced and $\mathrm{Ca}^{2+}$-induced $\mathrm{Ca}^{2+}$ release-associated neurotransmitter releases (40). Effects of LEV on $\mathrm{Ca}^{2+}$ channels have been widely studied $(41,42)$. Levetiracetam is also reported to modulate the presynaptic P/Q-type voltage-dependent calcium $\left(\mathrm{Ca}^{2+}\right)$ channel to reduce glutamate release in the dentate gyrus, the area of the hippocampus that regulates seizure activities (43). Similarly, LEV has been reported to inhibit neurotransmitter release via intracellular inhibition of presynaptic $\mathrm{Ca}^{2+}$ channels (44).

\section{LEVETIRACETAM AND SV2A}

Synaptic vesicle protein 2 (SV2) is a 12 trans-membrane integral protein present at all synaptic sites. It consists of three isoforms, $2 \mathrm{~A}, 2 \mathrm{~B}$, and $2 \mathrm{C}$. The SV2A isoform is most widely distributed, $2 \mathrm{~B}$ is brain specific, and $2 \mathrm{C}$ is the minor brain isoform. SV2 proteins have been proposed to act as transporters of common constituent of the vesicles, such as $\mathrm{Ca}^{2+}$ or ATP (45). SV2A has also been shown to interact with the presynaptic protein synaptotagmin, which is considered the $\mathrm{Ca}^{2+}$ sensor for regulation of $\mathrm{Ca}^{2+}$-dependent exocytosis of synaptic vesicles (46). SV2A is involved in controlling exocytosis of neurotransmitter-containing vesicles (47). SV2A is not essential for synaptic transmission, but SV2A knockout mice exhibit seizures (48). Thus, SV2A ligands could protect against seizures through effects on synaptic release mechanisms. Indeed, SV2 has been identified as the likely target for LEV. Studies have shown that the brain distribution of the LEV-binding site, as revealed by autoradiography, matches the equivalent distribution of SV2A as determined by immunocytochemistry $(45,49)$. Elegant studies have shown that SV2A is indeed the binding site for LEV in the brain $(50,51)$. Thus, LEV's interaction with SV2A is a leading mechanism of its anti-epileptic action.

\section{LEVETIRACETAM AND Ca ${ }^{2+}$ SIGNALING}

$\mathrm{Ca}^{2+}$ ions are major second messenger molecules that play a role in plethora of biological functions including neuronal excitability and synaptic plasticity $(6,52) . \mathrm{Ca}^{2+}$ levels are therefore tightly regulated to attain the high signal-to-noise ratio in cellular communications. Disturbances in $\mathrm{Ca}^{2+}$ homeostatic mechanisms resulting 
in elevated intracellular $\mathrm{Ca}^{2+}$ levels have been reported in multiple neurological disorders including stroke, movement disorders, and seizure pathologies $(6,52)$. Incessant $\mathrm{Ca}^{2+}$ entry into the neurons via the NMDA receptors during SE and persistent leak of $\mathrm{Ca}^{2+}$ from intracellular $\mathrm{Ca}^{2+}$ stores have now been firmly established in SE induced epilepsy $(6,52)$. Laboratory research has shown that blocking the ryanodine receptor-mediated $\mathrm{Ca}^{2+}$ leak from endoplasmic reticulum using dantrolene lowers the elevated $\mathrm{Ca}^{2+}$ post SE and prevents the development of epileptiform discharges in hippocampal neurons (53). Interestingly, LEV reduced intraneuronal $\mathrm{Ca}^{2+}$ levels by inhibiting ryanodine and $\mathrm{IP}_{3}$ receptor dependent $\mathrm{Ca}^{2+}$ release from endoplasmic reticulum (54). The ability of LEV to modulate the two major $\mathrm{Ca}^{2+}$-induced $\mathrm{Ca}^{2+}$ release systems demonstrated an important molecular effect of this agent on a major second messenger system in neurons and could possibly contribute to its unique mechanism of action. In addition, LEV has also been shown to inhibit $\mathrm{Ca}^{2+}$ entry by blocking the L-type $\mathrm{Ca}^{2+}$ channels in hippocampal neurons of spontaneously epileptic rats (55). There are other studies that report no action of LEV on L-type $\mathrm{Ca}^{2+}$ channels, but LEV has been shown to be selective toward $\mathrm{N}$-type $\mathrm{Ca}^{2+}$ channels' freshly isolated CA1 hippocampal neurons of rats (56). Thus, the effects on $\mathrm{Ca}^{2+}$ entry and release pathways are an important aspect of LEV's mechanism of action.

\section{LEVETIRACETAM AND EPILEPTOGENESIS}

The process by which healthy brain tissue is transformed by an injury into a hyperexcitable circuit of neurons giving rise to spontaneous seizures (acquired epilepsy) is called epileptogenesis (6). This transformation includes a myriad of neuronal plasticity changes including axonal sprouting, neuronal degeneration, neurogenesis, astrocytes activation, and changes in neurotransmitter release and their receptor response (6). Major second messenger systems that are activated after brain injury are suspected as initiating and sustaining these neuroplasticity changes that underlie epileptogenesis. Role of $\mathrm{Ca}^{2+}$ ions in epileptogenesis is well-established. Brain injury-induced protracted alterations in $\mathrm{Ca}^{2+}$ homeostasis are thought to trigger changes in protein transcription and gene expression that underlie abnormal synaptic plasticity changes expressed as seizure disorders and associated behavioral abnormality. Inhibition of $\mathrm{Ca}^{2+}$ elevations following SE are neuroprotective and produce an anti-epileptogenic effect $(53,57)$. Levetiracetam has been reported to limit epileptogenesis $(58,59)$. This effect could partly be attributed to LEV's effect on $\mathrm{Ca}^{2+}$ homeostasis, as discussed above. Thus, LEV significantly inhibited development of epileptic focus following kindling-induced epileptogenesis (59). Further, a significant inhibition of seizures even at 5 weeks following termination of LEV treatment was observed in spontaneously epileptic rats indicating that LEV possesses anti-epileptogenic properties (60). However, other studies have failed in observing LEV's anti-epileptogenic potential, for example 5-weeks of LEV treatment did not prevent development of seizures when administered $4 \mathrm{~h}$ after the onset of SE with seizure termination through diazepam (61). The ability of LEV to prevent development of seizures following SE makes it an important agent for the treatment of SE. Thus, LEV has important potential as an anti-epileptogenic agent that needs further elucidation.

\section{CONCLUDING REMARKS}

Levetiracetam is a unique anticonvulsant agent that has multiple mechanism of action that differentiates it from conventional anticonvulsant drugs. This makes it an ideal agent to add to the treatments for SE. Refractory SE is a major medical and neurological emergency associated with high morbidity and mortality. Levetiracetam offers a unique anticonvulsant treatment option to initiate for the treatment of refractory SE. Its low incidence of side-effects and sedative properties make it an ideal agent to consider in treating refractory SE. The availability of an intravenous preparation of LEV also facilitates its use in treating refractory SE. Further studies should confirm that LEV will also be a major first line drug for the treatment of SE, but at present it is not approved for this use. The unique anticonvulsant mechanisms of action of LEV make it an ideal agent to add to conventional anticonvulsant agents and to consider for the treatment of refractory SE and intractable seizure disorders.

\section{REFERENCES}

1. DeLorenzo RJ. Epidemiology and clinical presentation of status epilepticus. $A d v$ Neurol (2006) 97:199-215.

2. DeLorenzo RJ, Garnett LK, Towne AR, Waterhouse EJ, Boggs JG, Morton L, et al. Comparison of status epilepticus with prolonged seizure episodes lasting from 10 to 29 minutes. Epilepsia (1999) 40:164-9. doi:10.1111/j.1528-1157. 1999.tb02070.x

3. Lowenstein DH, Bleck T, Macdonald RL. It's time to revise the definition of status epilepticus. Epilepsia (1999) 40:120-2. doi:10.1111/j.1528-1157.1999.tb02000.x

4. Penberthy LT, Towne A, Garnett LK, Perlin JB, DeLorenzo RJ. Estimating the economic burden of status epilepticus to the health care system. Seizure (2005) 14:46-51. doi:10.1016/j.seizure.2004.06.001

5. DeLorenzo RJ, Kirmani B, Deshpande LS, Jakkampudi V, Towne AR, Waterhouse E, et al. Comparisons of the mortality and clinical presentations of status epilepticus in private practice community and university hospital settings in Richmond, Virginia. Seizure (2009) 18:405-11. doi:10.1016/j.seizure.2009.02.005

6. Delorenzo RJ, Sun DA, Deshpande LS. Cellular mechanisms underlying acquired epilepsy: the calcium hypothesis of the induction and maintenance of epilepsy. Pharmacol Ther (2005) 105:229-66. doi:10.1016/j.pharmthera.2004.10.004

7. Fountain NB. Status epilepticus: risk factors and complications. Epilepsia (2000) 41(Suppl 2):S23-30. doi:10.1111/j.1528-1157.2000.tb01521.x

8. Drislane FW. Presentation, evaluation, and treatment of nonconvulsive status epilepticus. Epilepsy Behav (2000) 1:301-14. doi:10.1006/ebeh.2000.0100

9. Fountain NB, Lothman EW. Pathophysiology of status epilepticus. J Clin Neurophysiol (1995) 12:326-42. doi:10.1097/00004691-199507000-00004

10. Hesdorffer DC, Logroscino G, Cascino G, Annegers JF, Hauser WA. Risk of unprovoked seizure after acute symptomatic seizure: effect of status epilepticus. Ann Neurol (1998) 44:908-12. doi:10.1002/ana.410440609

11. Lothman EW, Bertram EH III. Epileptogenic effects of status epilepticus. Epilepsia (1993) 34(Suppl 1):S59-70. doi:10.1111/j.1528-1157.1993.tb05907.x

12. Kanner AM. Epilepsy: psychiatric comorbidities and premature death in epilepsy. Nat Rev Neurol (2013) 9:606-8. doi:10.1038/nrneurol.2013.214

13. Mayer SA, Claassen J, Lokin J, Mendelsohn F, Dennis LJ, Fitzsimmons BF. Refractory status epilepticus: frequency, risk factors, and impact on outcome. Arch Neurol (2002) 59:205-10. doi:10.1001/archneur.59.2.205

14. Shorvon S. The treatment of status epilepticus. Curr Opin Neurol (2011) 24:165-70. doi:10.1097/WCO.0b013e3283446f31

15. Treiman DM, Meyers PD, Walton NY, Collins JF, Colling C, Rowan AJ, et al. A comparison of four treatments for generalized convulsive status epilepticus. Veterans Affairs Status Epilepticus Cooperative Study Group. N Engl J Med (1998) 339:792-8. doi:10.1056/NEJM199809173391202

16. Pellock JM, Marmarou A, DeLorenzo R. Time to treatment in prolonged seizure episodes. Epilepsy Behav (2004) 5:192-6. doi:10.1016/j.yebeh.2003.12.012

17. Lowenstein DH, Alldredge BK. Status epilepticus. N Engl J Med (1998) 338:970-6. doi:10.1056/NEJM199804023381407

18. Wasterlain CG, Chen JW. Mechanistic and pharmacologic aspects of status epilepticus and its treatment with new antiepileptic drugs. Epilepsia (2008) 49(Suppl 9):63-73. doi:10.1111/j.1528-1167.2008.01928.x 
19. Potschka H, Baltes S, Loscher W. Inhibition of multidrug transporters by verapamil or probenecid does not alter blood-brain barrier penetration of levetiracetam in rats. Epilepsy Res (2004) 58:85-91. doi:10.1016/j.eplepsyres. 2003.12.007

20. Kwan P, Brodie MJ. Potential role of drug transporters in the pathogenesis of medically intractable epilepsy. Epilepsia (2005) 46:224-35. doi:10.1111/j.00139580.2005.31904.x

21. Zelano J, Kumlien E. Levetiracetam as alternative stage two antiepileptic drug in status epilepticus: a systematic review. Seizure (2012) 21:233-6. doi:10.1016/ j.seizure.2012.01.008

22. Misra UK, Kalita J, Maurya PK. Levetiracetam versus lorazepam in status epilepticus: a randomized, open labeled pilot study. J Neurol (2012) 259:645-8. doi:10.1007/s00415-011-6227-2

23. Crepeau AZ, Treiman DM. Levetiracetam: a comprehensive review. Expert Rev Neurother (2010) 10:159-71. doi:10.1586/ern.10.3

24. Eue S, Grumbt M, Muller M, Schulze A. Two years of experience in the treatment of status epilepticus with intravenous levetiracetam. Epilepsy Behav (2009) 15:467-9. doi:10.1016/j.yebeh.2009.05.020

25. Kirmani BF, Mungall D, Ling G. Role of intravenous levetiracetam in seizure prophylaxis of severe traumatic brain injury patients. Front Neurol (2013) 4:170. doi:10.3389/fneur.2013.00170

26. McTague A, Kneen R, Kumar R, Spinty S, Appleton R. Intravenous levetiracetam in acute repetitive seizures and status epilepticus in children: experience from a children's hospital. Seizure (2012) 21:529-34. doi:10.1016/j.seizure.2012. 05.010

27. Moddel G, Bunten S, Dobis C, Kovac S, Dogan M, Fischera M, et al. Intravenous levetiracetam: a new treatment alternative for refractory status epilepticus. J Neurol Neurosurg Psychiatry (2009) 80:689-92. doi:10.1136/jnnp.2008.145458

28. Shin HW, Davis R. Review of levetiracetam as a first line treatment in status epilepticus in the adult patients - what do we know so far? Front Neurol (2013) 4:111. doi:10.3389/fneur.2013.00111

29. Zesiewicz TA, Sullivan KL, Hauser RA, Sanchez-Ramos J. Open-label pilot study of levetiracetam (Keppra) for the treatment of chorea in Huntington's disease. Mov Disord (2006) 21:1998-2001. doi:10.1002/mds.21061

30. Woods SW, Saksa JR, Baker CB, Cohen SJ, Tek C. Effects of levetiracetam on tardive dyskinesia: a randomized, double-blind, placebo-controlled study. J Clin Psychiatry (2008) 69:546-54. doi:10.4088/JCP.v69n0405

31. Hedderick EF, Morris CM, Singer HS. Double-blind, crossover study of clonidine and levetiracetam in Tourette syndrome. Pediatr Neurol (2009) 40:420-5. doi:10.1016/j.pediatrneurol.2008.12.014

32. Farooq MU, Bhatt A, Majid A, Gupta R, Khasnis A, Kassab MY. Levetiracetam for managing neurologic and psychiatric disorders. Am J Health Syst Pharm (2009) 66:541-61. doi:10.2146/ajhp070607

33. Shetty AK. Prospects of levetiracetam as a neuroprotective drug against status epilepticus, traumatic brain injury, and stroke. Front Neurol (2013) 4:172. doi:10.3389/fneur.2013.00172

34. Klitgaard H, Matagne A, Gobert J, Wulfert E. Evidence for a unique profile of levetiracetam in rodent models of seizures and epilepsy. Eur J Pharmacol (1998) 353:191-206. doi:10.1016/S0014-2999(98)00410-5

35. Gower AJ, Hirsch E, Boehrer A, Noyer M, Marescaux C. Effects of levetiracetam, a novel antiepileptic drug, on convulsant activity in two genetic rat models of epilepsy. Epilepsy Res (1995) 22:207-13. doi:10.1016/0920-1211(95)00077-1

36. De Smedt T, Raedt R, Vonck K, Boon P. Levetiracetam: the profile of a novel anticonvulsant drug-part I: preclinical data. CNS Drug Rev (2007) 13:43-56. doi:10.1111/j.1527-3458.2007.00005.x

37. Klitgaard H, Verdru P. Levetiracetam: the first SV2A ligand for the treatment of epilepsy. Expert Opin Drug Discov (2007) 2:1537-45. doi:10.1517/17460441.2. 11.1537

38. Tong X, Patsalos PN. A microdialysis study of the novel antiepileptic drug levetiracetam: extracellular pharmacokinetics and effect on taurine in rat brain. Br J Pharmacol (2001) 133:867-74. doi:10.1038/sj.bjp.0704141

39. Wakita M, Kotani N, Kogure K, Akaike N. Inhibition of excitatory synaptic transmission in hippocampal neurons by levetiracetam involves $\mathrm{Zn} 2+$-dependent GABAA receptor-mediated presynaptic modulation. J Pharmacol Exp Ther (2014) 348(2):246-59. doi:10.1124/jpet.113.208751

40. Fukuyama K, Tanahashi S, Nakagawa M, Yamamura S, Motomura E, Shiroyama $\mathrm{T}$, et al. Levetiracetam inhibits neurotransmitter release associated with CICR. Neurosci Lett (2012) 518:69-74. doi:10.1016/j.neulet.2012.03.056
41. Niespodziany I, Klitgaard H, Margineanu DG. Levetiracetam inhibits the highvoltage-activated $\mathrm{Ca}(2+)$ current in pyramidal neurones of rat hippocampal slices. Neurosci Lett (2001) 306:5-8. doi:10.1016/S0304-3940(01)01884-5

42. Pisani A, Bonsi P, Martella G, De Persis C, Costa C, Pisani F, et al. Intracellular calcium increase in epileptiform activity: modulation by levetiracetam and lamotrigine. Epilepsia (2004) 45:719-28. doi:10.1111/j.0013-9580.2004.02204.x

43. Lee CY, Chen CC, Liou HH. Levetiracetam inhibits glutamate transmission through presynaptic P/Q-type calcium channels on the granule cells of the dentate gyrus. Br J Pharmacol (2009) 158:1753-62. doi:10.1111/j.1476-5381.2009. 00463.x

44. Vogl C, Mochida S, Wolff C, Whalley BJ, Stephens GJ. The synaptic vesicle glycoprotein 2A ligand levetiracetam inhibits presynaptic $\mathrm{Ca} 2+$ channels through an intracellular pathway. Mol Pharmacol (2012) 82:199-208. doi:10.1124/mol.111.076687

45. Bajjalieh SM, Frantz GD, Weimann JM, McConnell SK, Scheller RH. Differential expression of synaptic vesicle protein 2 (SV2) isoforms. J Neurosci (1994) 14:5223-35.

46. Pyle RA, Schivell AE, Hidaka H, Bajjalieh SM. Phosphorylation of synaptic vesicle protein 2 modulates binding to synaptotagmin. J Biol Chem (2000) 275:17195-200. doi:10.1074/jbc.M000674200

47. Nowack A, Yao J, Custer KL, Bajjalieh SM. SV2 regulates neurotransmitter release via multiple mechanisms. Am J Physiol Cell Physiol (2010) 299:C960-7. doi:10.1152/ajpcell.00259.2010

48. Crowder KM, Gunther JM, Jones TA, Hale BD, Zhang HZ, Peterson MR, et al. Abnormal neurotransmission in mice lacking synaptic vesicle protein $2 \mathrm{~A}$ (SV2A). Proc Natl Acad Sci U S A (1999) 96:15268-73. doi:10.1073/pnas.96.26. 15268

49. Gillard M, Fuks B, Michel P, Vertongen P, Massingham R, Chatelain P. Binding characteristics of $[3 \mathrm{H}] \mathrm{ucb} 30889$ to levetiracetam binding sites in rat brain. Eur J Pharmacol (2003) 478:1-9. doi:10.1016/j.ejphar.2003.08.032

50. Gillard M, Chatelain P, Fuks B. Binding characteristics of levetiracetam to synaptic vesicle protein $2 \mathrm{~A}$ (SV2A) in human brain and in CHO cells expressing the human recombinant protein. Eur J Pharmacol (2006) 536:102-8. doi:10.1016/j.ejphar.2006.02.022

51. Lynch BA, Lambeng N, Nocka K, Kensel-Hammes P, Bajjalieh SM, Matagne A, et al. The synaptic vesicle protein SV2A is the binding site for the antiepileptic drug levetiracetam. Proc Natl Acad Sci U S A (2004) 101:9861-6. doi:10.1073/ pnas.0308208101

52. Nagarkatti N, Deshpande LS, DeLorenzo RJ. Development of the calcium plateau following status epilepticus: role of calcium in epileptogenesis. Expert Rev Neurother (2009) 9:813-24. doi:10.1586/ern.09.21

53. Nagarkatti N, Deshpande LS, Carter DS, DeLorenzo RJ. Dantrolene inhibits the calcium plateau and prevents the development of spontaneous recurrent epileptiform discharges following in vitro status epilepticus. Eur J Neurosci (2010) 32:80-8. doi:10.1111/j.1460-9568.2010.07262.x

54. Nagarkatti N, Deshpande LS, DeLorenzo RJ. Levetiracetam inhibits both ryanodine and IP3 receptor activated calcium induced calcium release in hippocampal neurons in culture. Neurosci Lett (2008) 436:289-93. doi:10.1016/j.neulet. 2008.02.076

55. Yan HD, Ishihara K, Seki T, Hanaya R, Kurisu K, Arita K, et al. Inhibitory effects of levetiracetam on the high-voltage-activated L-type $\mathrm{Ca}(2)(+)$ channels in hippocampal CA3 neurons of spontaneously epileptic rat (SER). Brain Res Bull (2013) 90:142-8. doi:10.1016/j.brainresbull.2012.10.006

56. Lukyanetz EA, Shkryl VM, Kostyuk PG. Selective blockade of N-type calcium channels by levetiracetam. Epilepsia (2002) 43:9-18. doi:10.1046/j.1528-1157. 2002.24501.x

57. Deshpande LS, Nagarkatti N, Ziobro JM, Sombati S, DeLorenzo RJ. Carisbamate prevents the development and expression of spontaneous recurrent epileptiform discharges and is neuroprotective in cultured hippocampal neurons. Epilepsia (2008) 49:1795-802. doi:10.1111/j.1528-1167.2008.01667.x

58. Klitgaard H, Pitkanen A. Antiepileptogenesis, neuroprotection, and disease modification in the treatment of epilepsy: focus on levetiracetam. Epileptic Disord (2003) 5(Suppl 1):S9-16.

59. Loscher W, Honack D, Rundfeldt C. Antiepileptogenic effects of the novel anticonvulsant levetiracetam (ucb L059) in the kindling model of temporal lobe epilepsy. J Pharmacol Exp Ther (1998) 284:474-9.

60. Yan HD, Ji-qun C, Ishihara K, Nagayama T, Serikawa T, Sasa M. Separation of antiepileptogenic and antiseizure effects of levetiracetam in the spontaneously 
epileptic rat (SER). Epilepsia (2005) 46:1170-7. doi:10.1111/j.1528-1167.2005. 35204.x

61. Brandt C, Glien M, Gastens AM, Fedrowitz M, Bethmann K, Volk HA, et al. Prophylactic treatment with levetiracetam after status epilepticus: lack of effect on epileptogenesis, neuronal damage, and behavioral alterations in rats. Neuropharmacology (2007) 53:207-21. doi:10.1016/j.neuropharm.2007. 05.001

Conflict of Interest Statement: The authors declare that the research was conducted in the absence of any commercial or financial relationships that could be construed as a potential conflict of interest.
Received: 20 December 2013; paper pending published: 13 January 2014; accepted: 17 January 2014; published online: 31 January 2014.

Citation: Deshpande LS and DeLorenzo RJ (2014) Mechanisms of levetiracetam in the control of status epilepticus and epilepsy. Front. Neurol. 5:11. doi: 10.3389/fneur.2014.00011

This article was submitted to Epilepsy, a section of the journal Frontiers in Neurology. Copyright $(2) 2014$ Deshpande and DeLorenzo. This is an open-access article distributed under the terms of the Creative Commons Attribution License (CC BY). The use, distribution or reproduction in other forums is permitted, provided the original author(s) or licensor are credited and that the original publication in this journal is cited, in accordance with accepted academic practice. No use, distribution or reproduction is permitted which does not comply with these terms. 